\title{
Crush injury and rhabdomyolysis
}

\author{
Darren J. Malinoski, MD ${ }^{\mathrm{a}, \mathrm{b}, *}$, Matthew S. Slater, MD ${ }^{\mathrm{c}}$, \\ Richard J. Mullins, MD ${ }^{\mathrm{a}, \mathrm{b}, \mathrm{d}}$

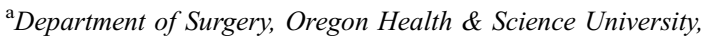 \\ 3181 Southwest Sam Jackson Park Road, Portland, OR 97201-3098, USA \\ ${ }^{\mathrm{b}}$ Section of Trauma/Critical Care, Oregon Health \& Science University, \\ 3181 Southwest Sam Jackson Park Road, Portland, OR, 97201-3098, USA \\ ${ }^{\mathrm{c}}$ Division of Cardiothoracic Surgery, Oregon Health \& Science University, \\ 3181 Southwest Sam Jackson Park Road, Portland, OR 97201-3098, USA \\ ${ }^{\mathrm{d}}$ Division of General Surgery, Oregon Health \& Science University, \\ 3181 Southwest Sam Jackson Park Road, Portland, OR 97201-3098, USA
}

Although clinical syndromes consistent with rhabdomyolysis were recognized in the late 19th and early 20th centuries, the modern history of the crush syndrome begins with Bywaters' and Beal's classic description of the entrapped bombing victims of London during World War II [1-4]. They reported five cases of crush injury, in which victims had one or more of their extremities trapped under debris for prolonged periods of time. All five patients presented in shock, had swollen extremities, developed dark urine, progressed to renal failure, and eventually died. Histologic examination of the kidney revealed tubular necrosis and pigmented casts. In 1944, Bywaters and Stead identified myoglobin as the urinary pigment and proposed its role in the development of renal failure [5].

Large numbers of patients with crush injuries and rhabdomyolysis have been reported after the collapse of mines [6,7], severe beatings [8], and earthquakes [9-15]. In the United States, alcohol intoxication associated with prolonged muscle compression and seizures is the most common etiology of rhabdomyolysis [16]. Serum creatine kinase (CK) levels correlate with the degree of muscle injury [14] and can be used to assess the severity of rhabdomyolysis. Acute renal failure (ARF) is one of the most serious consequences of rhabdomyolysis and occurs in $4 \%$ to $33 \%$ of cases, carrying with it a mortality rate of $3 \%$ to $50 \%$ [17]. Rhabdomyolysis accounts for $5 \%$ to $7 \%$ of all cases of ARF in the United States [18].

This article focuses on the pathophysiology and treatment of myoglobinuric renal failure caused by traumatic rhabdomyolysis and crush injuries.

* Corresponding author. Department of Surgery, Oregon Health \& Science University, 3181 Southwest Sam Jackson Park Road, Portland, OR 97201-3098.

E-mail address: malinosk@ohsu.edu (D.J. Malinoski). 


\section{Etiologies}

Rhabdomyolysis is the liberation of components of injured skeletal muscle into the circulation [19]. There are many etiologies of rhabdomyolysis, but this article focuses on those most likely to be encountered in a trauma or surgical setting.

Direct compression of muscle leading to a local crush injury is the most common mechanism of traumatic rhabdomyolysis. Compression causes muscle ischemia, as tissue pressure rises to a level that exceeds capillary perfusion pressure. When the compression is relieved, the muscle tissue is reperfused. Muscle ischemia followed by reperfusion (ischemia-reperfusion injury) represents the fundamental pathophysiologic mechanism of rhabdomyolysis and is discussed extensively.

Acute alcohol intoxication with subsequent collapse, immobility, and coma is the most common etiologic factor of direct muscle compression [16,18]. Improper operative positioning using the extended lithotomy and lateral decubitus positions [20-26], blunt trauma to the extremities and torso caused by beatings or sudden automobile deceleration, and Pneumatic Antishock Garments (PASG) also lead to muscle compression and can cause varying degrees of rhabdomyolysis $[8,17]$. Earthquakes, landslides, and building collapse are catastrophes that produce large numbers of casualties with crush injuries and rhabdomyolysis.

Vascular compromise of an extremity because of arterial thrombosis, embolus, traumatic interruption, or external compression is another common cause of ischemic muscle injury and rhabdomyolysis. Venous injuries or thromboses also can lead to venous hypertension, which further decreases the capillary perfusion pressure. The duration of ischemia determines the degree of muscle injury. Skeletal muscle can tolerate warm ischemia for up to 2 hours without permanent, histologic damage. Two to four hours of ischemia lead to irreversible anatomic and functional changes, and muscle necrosis usually occurs by 6 hours of ischemia. By 24 hours, histologic changes caused by ischemia-reperfusion injury are maximal $[17,27,28]$.

Soft-tissue infections also can cause rhabdomyolysis. Legionella and Streptococcus species are the most common bacterial agents, but tularemia, Staphylococcus species, and Salmonella species are also responsible. Influenza is the most common viral etiology of rhabdomyolysis, but HIV, Coxsackie virus, and EpsteinBarr virus also have been implicated. Direct invasion of muscle cells and toxin generation have been proposed as two possible mechanisms of muscle injury because of either viral or bacterial agents. The risk of acute renal failure secondary to severe rhabdomyolysis after an infection ranges from $25 \%$ to $100 \%$ [29].

Electrical injuries from lightning strikes or high-voltage power lines have the potential to produce enough rhabdomyolysis to cause myoglobinuric renal failure. Muscle is injured directly by the electrical current (electroporation) and by the high temperatures that are generated [30,31]. Blood vessels also may coagulate, resulting in additional ischemic damage to the muscle. Up to $10 \%$ of patients with severe electrical injuries can develop renal failure.

Steroids and neuromuscular blockade have been associated with rhabdomyolysis, although the exact mechanism is unknown [32]. Cushing first described the association between steroid excess and muscular weakness in 1932 [33]. More 
recently, muscle weakness after long-term neuromuscular blockade with vecuronium has been reported [34]. CK levels were elevated in $76 \%$ of asthmatics who were treated with both high-dose steroids and vecuronium. [35]

\section{Pathogenesis of muscle injury}

A critical relationship exists between the intracellular concentrations of sodium $\left(\mathrm{Na}^{+}\right)$and calcium $\left(\mathrm{Ca}^{++}\right)$ions. A sarcolemmic sodium-potassium $(\mathrm{Na} / \mathrm{K})$ ATPase regulates the intracellular concentration of $\mathrm{Na}^{+}$, keeping it at approximately $10 \mathrm{mEq} / \mathrm{L}$. A low $\mathrm{Na}^{+}$level creates a concentration gradient between the intraand extracellular environments, which facilitates the efflux of $\mathrm{Ca}^{++}$as it is exchanged for $\mathrm{Na}^{+}$by way of a separate ion channel [36]. This maintains the intracellular $\mathrm{Ca}^{++}$concentration at a level several orders of magnitude less than the extracellular fluid [17]. Calcium also is transported actively into the sarcolemmal reticulum and mitochondria [19].

Muscle compression leads to mechanical stress, which opens stretch-activated channels in the muscle cell membrane [37]. This results in the influx of fluid and electrolytes, including $\mathrm{Na}^{+}$and $\mathrm{Ca}^{++}$. Cells swell, and their intracellular $\mathrm{Ca}^{++}$ concentration rises, resulting in several pathologic processes (Fig. 1). An increase in the activity of cytoplasmic neutral proteases leads to the degradation of myofibrillar proteins [38]; $\mathrm{Ca}^{++}$-dependent phosphorylases are activated, and cell membranes are degraded [39]. Additionally, nucleases are activated, and mitochondrial ATP production is diminished because of an inhibition of cellular respiration [40].

Muscle ischemia caused by prolonged compression or vascular injury results in anaerobic metabolism and a further decrease in ATP production. This diminishes the activity of the $\mathrm{Na} / \mathrm{K}$ ATPase, which leads to the accumulation of intracellular

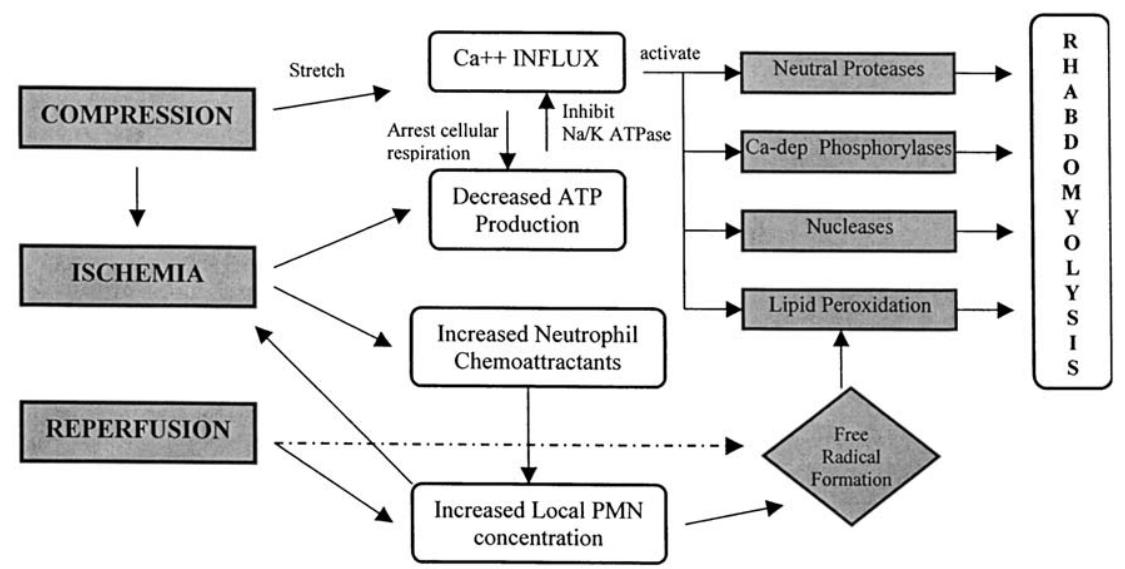

Fig. 1. The pathogenesis of rhabdomyolysis. 
fluid and further increases the intracellular $\mathrm{Ca}^{++}$concentration. In addition, increased concentrations of neutrophil chemoattractants are present in postischemic tissues, which results in a high local concentration of activated neutrophils once reperfusion is initiated. These neutrophils damage reperfused tissue by releasing proteolytic enzymes, generating free radicals [41], producing large amounts of hypochlorous acid, and by increasing microvascular resistance [42].

Reperfusion of ischemic tissue after the release of entrapped victims or the reestablishment of vascular flow results in an ischemia-reperfusion injury. In addition to delivering activated neutrophils to previously ischemic tissue, reperfusion leads to the conversion of oxygen and hypoxanthine to xanthine by xanthine oxidase, with the generation of superoxide anions, which are highly reactive oxygen-derived free radicals [43].

Free radicals are potent oxidizing agents that damage intracellular and extracellular molecules when their concentrations become excessive. Lipid peroxidation occurs when free radicals oxidize and damage the lipid bilayer of cell membranes. The ferrous-ferric ion pair provided by iron within the porphyrin ring in myoglobin catalyzes this process and facilitates widespread lipid peroxidation in muscle tissue [44]. Cell membrane degradation impairs the normal permeability of the cell and results in further cellular edema, $\mathrm{Ca}^{++}$influx, and $\mathrm{Na}^{+}$influx. Cell lysis follows, and the intracellular contents of the muscle cells are released into the circulation.

Lipid peroxidation leads to cellular membrane leakiness, and, when combined with a reduction in active ionic extrusion caused by the depletion of ATP, causes cellular swelling and an accumulation of fluid in the interstitial space $[45,46]$. Three hours of ischemia followed by reperfusion appear to be the minimum requisites for this effect [47-49]. In muscle groups confined in tight, fibrous sheaths with low compliance, such as the calf and forearm, intracompartmental pressure rises rapidly [50]. When this pressure exceeds the arteriolar-perfusion pressure, muscle tamponade and myoneuronal damage occur, resulting in compartment syndrome. Signs and symptoms of compartment syndrome include a tense, swollen muscle compartment, pain with passive stretch (the most sensitive finding), paresthesias or anesthesia, weakness or paralysis of the affected extremity, and, in late stages, diminished peripheral pulses. Palpable pulses, however, often are found in the presence of significantly elevated compartment pressures and should not lead one to dismiss the diagnosis of compartment syndrome.

\section{Crush syndrome}

After muscle compression is relieved or vascular interruption is corrected, the cellular contents of the affected muscle tissue are released into the circulation. Large volumes of intravascular fluid also can be sequestered in the involved extremities because of increased capillary permeability. The systemic manifestations of rhabdomyolysis, caused by hypovolemia and toxin exposure, are the components of the crush syndrome. 
Hypovolemia is often the first manifestation of the crush syndrome. In 1931, Blalock was able to show that large volumes of plasma accumulated in traumatized extremities, depleting intravascular volume and resulting in shock [51]. Bywaters and Beall recognized shock as a component of the crush syndrome in 1941 [3]. In a landmark animal experiment, Bywaters and Popjak demonstrated that several hours of hind limb ischemia created by a tourniquet, followed by restoration of blood flow, resulted in cold, firm, edematous, and paralyzed extremities. Although the extremities were ischemic, the rabbits did not experience any significant physiologic derangements. After reperfusion occurred, however, their blood became hemoconcentrated and their blood urea nitrogen levels rose. When both extremities were involved, the animals died from hypovolemic shock [52]. Clinical observations in human studies also have demonstrated that large volumes of fluid can leak into the interstitial space and cause hypotension $[3,53]$. In a series of 372 patients with crush syndrome, Oda [14] found that hypovolemic shock was the most common cause of death during the first 4 days after crush injury $(23 / 35,66 \%)$ (Fig. 2).

In addition to intravascular depletion, patients with the crush syndrome are faced with a large toxin load and can develop life-threatening electrolyte abnormalities (Table 1). Hypocalcemia results from the influx of $\mathrm{Ca}^{++}$into the affected muscle tissue. This becomes dangerous when combined with hyperkalemia and acidemia, both of which can occur upon reperfusion of ischemic tissue. Hyperkalemia and its associated cardiotoxicity represent the second most common cause of early deaths following crush injury [14]. Volume replacement is the mainstay of

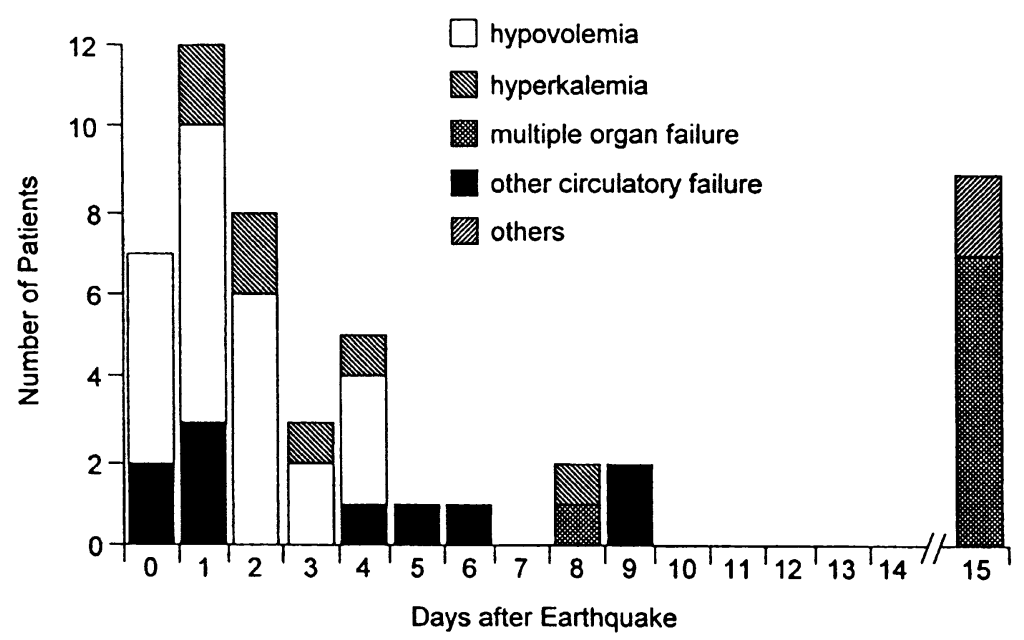

Fig. 2. The causes of death in 50 patients with the crush syndrome following the Hanshin-Awaji Earthquake. Deaths from hypovolemia and hyperkalemia were the most common in the early period, while sepsis leading to multiple organ failure was responsible for most of the late deaths. (Adapted from Oda J, Tanaka H, Yoshioka T, et al. Analysis of 372 patients with crush syndrome caused by the Hanshin-Awaji Earthquake. J Trauma 1997;(42):470-6; with permission.) 
Table 1

Intracellular contents released during rhabdomyolysis and their effects

\begin{tabular}{ll}
\hline Agent & Effect \\
\hline Potassium & $\begin{array}{l}\text { Hyperkalemia and cardiotoxicity, provoked by hypocalcemia } \\
\text { and hypovolemia }\end{array}$ \\
Phosphate & $\begin{array}{l}\text { Hyperphosphatemia, worsening of hypocalcemia, and } \\
\text { metastatic calcification }\end{array}$ \\
Organic acids & Metabolic acidosis and aciduria \\
Myoglobin & Myoglobinuria and nephrotoxicity \\
Creatine kinase (CK) & Elevation of serum CK levels \\
Thromboplastin & Disseminated intravascular coagulation \\
\hline
\end{tabular}

treatment for patients with crush injuries and rhabdomyolysis, because it addresses the two main early threats to survival, hypovolemic shock and hyperkalemia.

Hyperphosphatemia also follows rhabdomyolysis and can worsen the aforementioned hypocalcemia by depressing levels of 1,25-dihydroxycholecalciferol $\left(1,25-\left(\mathrm{OH}_{2}\right)-\mathrm{D}\right)$. Tissue thromboplastin levels also increase and can lead to disseminated intravascular coagulation (DIC); patients often present with depressed platelet levels because of DIC-related consumption [53]. Large amounts of myoglobin also are released into the general circulation and represent a significant threat to the kidney. If intravenous fluid replacement is inadequate or delayed for more than 6 hours, patients are also at significant risk for developing renal failure [50].

\section{Pathophysiology of renal injury}

Four percent to $33 \%$ of patients with rhabdomyolysis will develop ARF (a decline in renal function that requires some form of renal replacement therapy) with an associated mortality rate of $3 \%$ to $50 \%[17,18]$. There are three main mechanisms by which rhabdomyolysis can lead to the development of renal failure: decreased renal perfusion, cast formation with tubular obstruction, and the direct toxic effects of myoglobin on the renal tubules.

Decreased renal perfusion results from the inherent hypovolemia of the crush syndrome, the stimulation of the sympathetic nervous system and the reninangiotensin-aldosterone axis and renal vasoconstriction in the presence of myoglobin. Vasoconstrictors released in the presence of myoglobin include plasma endothelin-1 and platelet activating factor (PAF) [54-56]. Endothelins reduce glomerular filtration by constricting the afferent and efferent arterioles. Administration of bosentan, an endothelin receptor antagonist, prevented renal failure in rats with myoglobinuria [57].

Platelet activating factor is produced in the mesangial and glomerular cells and causes vascular smooth muscle constriction [58]. Increased levels have been observed with myoglobinuria, and renal injury is lessened when PAF receptors are blocked in experimental models of myoglobin-induced renal failure [54,59-61]. 
Myoglobin is a respiratory pigment protein that comprises $1 \%$ to $3 \%$ of the wet weight of skeletal muscle [19]. It has a molecular weight of 17,800 d and is filtered readily by the kidney. At the center of the myoglobin molecule is a single heme prosthetic group with an iron atom that serves as an oxygen-binding site [17]. Low levels of circulating myoglobin are (50\% to $85 \%$ ) bound mostly to haptoglobin and $\alpha_{2}-$ globulin and are cleared from the circulation by the reticuloendothelial system [62]. When circulating levels of myoglobin are elevated, as occurs after rhabdomyolysis, the binding capacity of haptoglobin is saturated, and free plasma levels rise. Plasma levels greater than 0.5 to $1.5 \mathrm{mg} / \mathrm{dL}$ are filtered by the kidney, resulting in myoglobinuria. Normal urinary myoglobin levels are less than $5 \mathrm{ng} / \mathrm{mL}$. Myoglobin is not reabsorbed in the renal tubules and increases in concentration as water is reabsorbed from the tubular filtrate, resulting in dark, teacolored urine. The presence of myoglobin in the urine can be confirmed with a positive urine dipstick, which reacts with the heme groups of both myoglobin and hemoglobin. The absence of red cells on microscopy confirms that the discolored urine is caused by myoglobin. Myoglobinuria and hemoglobinuria can occur simultaneously, however.

Myoglobin cast formation and tubular obstruction occur in patients with acidic urine and a high concentration of myoglobin in the renal tubules. The myoglobin reacts with the Tamm-Horsfell (THP) protein and precipitates, forming casts. This binding is enhanced under acidic conditions, and urinary alkalinization with sodium bicarbonate has been shown to reduce cast formation [63]. Whether this effect is directly caused by the alkaline $\mathrm{pH}$ or the induced solute diuresis is not certain. The hypothesis that myoglobin casts obstruct urine flow $[63,64]$ and cause a transtubular leakage of glomerular filtrate [65] has been promoted widely. Micropuncture experiments have shown that intratubular pressures are low, however, and that perfusion of the tubule with buffer at low pressures easily removes the casts [66].

The direct toxic effect of myoglobin is likely the main component in the development of renal failure after rhabdomyolysis. There is an increasing body of evidence that supports free radical-mediated renal injury, especially to the proximal tubule. It has been shown that endogenous radical scavenging agents are depleted during myoglobinuria-induced renal failure, while antioxidant administration can improve renal function [67-70]. Myoglobin separates into protein and ferrihemate moieties in an acidic environment [71]. Iron catalyzes the formation of free radicals by ways of the Fenton reaction, which, in turn, leads to lipid peroxidation in the renal tubules [70]. The heme group of the myoglobin molecule itself also may promote lipid peroxidation during redox cycling between its different oxidation states. The reactivity of ferryl myoglobin, which is responsible for inducing lipid peroxidation, is attenuated markedly at alkaline $\mathrm{pH}$ [72]. This further supports the role of an induced alkaline diuresis in the treatment of patients with rhabdomyolysis. Additionally, desferrioxamine (DFO), an iron chelator, has been shown to protect against renal dysfunction in animal models of rhabdomyolysis $[68,73]$. This protects against the exposure to free iron and the redox cycling of myoglobin, and thus lipid peroxidation [74]. 
Additional vasoconstrictors also are generated by the presence of myoglobinuria and contribute to the renal dysfunction following rhabdomyolysis. $\mathrm{F}_{2}-$ isoprostanes are a group of prostaglandin-like compounds that are formed during free radical-induced lipid peroxidation [75]. They have been found to be elevated in people with rhabdomyolysis [76] and are themselves renal vasoconstrictors. Nitric oxide (NO) is another vasoactive mediator that is involved in maintaining renal blood flow [77]. NO donors have been found to preserve renal function in the face of heme protein injury, while NO synthase inhibitors aggravate injury [78]. This may be attributable to the ability of myoglobin to scavenge NO [79] or prevent its redox cycling [80].

\section{Diagnosis}

Early diagnosis is crucial in patients with rhabdomyolysis. Patients who have sustained significant soft tissue injury (because of crush injuries or prolonged immobilization) or ischemia-reperfusion injury (because of vascular interruption) are at risk of developing rhabdomyolysis, myoglobinuria, and renal failure. Patients often present with painful, swollen extremities and should be monitored for the development of an extremity compartment syndrome. Physical examination of patients with central nervous system injury, intoxication, or multiple life-threatening injuries can be difficult and unreliable. Dark, tea-colored urine that is dipstick positive for blood despite the absence of red blood cells on microscopy is suggestive of myoglobinuria and rhabdomyolysis. The most rapid and least expensive screening test for rhabdomyolysis is the serum CK level. Patients who are believed to be at risk on the basis of history and physical examination should have their urine output monitored and serial serum $\mathrm{CK}$ levels drawn. When serum CK levels are elevated, it is important to rule out a cardiac muscle injury, such as a myocardial infarction or contusion, as the source of the enzyme elevation.

\section{Management}

Preventing the systemic and renal complications of the crush syndrome requires early, vigorous fluid resuscitation, preferably started at the site of injury before extrication [81]. Better et al [50,53] demonstrated the importance of early fluid resuscitation by reporting their differing treatments of two groups of patients (one in 1979 and one in 1982) with extensive rhabdomyolysis as a result of the collapse of buildings. There were a total of 15 patients in the two groups who suffered roughly the same degree of crush injury to the lower extremities after being trapped for a mean of 12 hours. The seven men in 1979 did not receive aggressive fluid resuscitation until at least 6 hours after extrication. Despite receiving adequate volume replacement (average $11 \mathrm{~L}$ of intravenous fluids per day until central venous pressure began to rise), all seven men developed ARF 
and required dialysis. In contrast, seven of the eight men treated in 1982 received intravenous saline before the completion of extrication and were evacuated to a hospital within 2 hours, where they received a forced mannitol-alkaline diuresis with a target urine output of $300 \mathrm{~mL}$ per hour. All seven had serum CK levels greater than 30,000 U/L, and none developed azotemia or ARF. One of the eight men experienced a delay of 24 hours in the diagnosis and treatment of his rhabdomyolysis and did develop ARF. Although the authors concluded that early, aggressive volume replacement followed by a forced mannitol-alkaline diuresis may protect against ARF in patients with traumatic rhabdomyolysis, they recognized that the relative benefits of early fluid resuscitation versus a forced solute diuresis are unclear and that a goal of $300 \mathrm{~mL}$ per hour of urine output may be more than required.

The benefits of mannitol to induce a solute diuresis have been established in several experimental studies. Mannitol is an osmotic diuretic, promoting an increase in urine output and the washout of tubular myoglobin, and it is a volume expander. Because mannitol can cause volume overload in patients with marginal cardiac function and established ARF, it should not be used until urine output has been established. Mannitol also has been shown to reduce intracompartmental pressure in a canine model of compartment syndrome [82], and therefore it may be a conservative alternative to fasciotomy. In addition, mannitol is an effective hydroxyl-free radical scavenger that may protect the kidney from oxidant injury [73]. Because mannitol can produce a hyperosmolar state and electrolyte derangements, frequent monitoring of serum electrolytes, osmolarity, and patient volume status is recommended.

Alkalinization of the urine with sodium bicarbonate to prevent the development of ARF after crush injuries and rhabdomyolysis has been supported by numerous animal studies [63,69], case reports [25,53,83-85], and retrospective clinical studies $[50,53,84]$. Bicarbonate assists in the creation of alkaline urine, which serves to decrease cast formation and lessen the direct toxic effects of myoglobin [63]. Moore et al [72] found that alkalinization inhibits redox cycling of myoglobin and lipid peroxidation in rhabdomyolysis. In isolated perfused kidneys, myoglobin induced renal vasoconstriction only at an acid $\mathrm{pH}$ [86]. Ron and Michaelson [53] found that large amounts of bicarbonate were required to alkalinize the urine of patients with rhabdomyolysis. An average of $685 \mathrm{mEq}$ of bicarbonate was administered during the first 60 hours of treatment to maintain a urine $\mathrm{pH}$ of greater than 6.5. To prevent alkalemia, an average of 1.5 doses of $250 \mathrm{mg}$ of acetazolamide was needed, and plasma $\mathrm{pH}$ did not exceed 7.45 in any patient. Other authors have argued that large volume infusion of crystalloid alone can produce a sufficient solute diuresis to maintain alkalotic urine [8,19].

A retrospective analysis of 24 nonrandomized patients with rhabdomyolysis of different causes attempted to determine if there was a benefit to treatment with saline, mannitol, and bicarbonate (group 1) over that of saline alone (group 2) [87]. The authors concluded that mannitol and bicarbonate were not necessary to avoid the development of renal failure. None of the 24 patients developed renal dysfunction, however, and their degree of muscle injury was low (average 
$\mathrm{CPK}=2750 \mathrm{U} / \mathrm{L})$. The results of this study neither support nor negate the use of a forced alkaline diuresis. There is a need for a prospective randomized controlled trial comparing the effectiveness of crystalloid, mannitol, and bicarbonate with that of standard crystalloid resuscitation. Despite the fact that class 1 evidence in support of using a forced alkaline diuresis is lacking, bicarbonate can ameliorate the systemic acidosis and hyperkalemia that occur during the crush syndrome, and bicarbonate may be useful in patients with the crush syndrome regardless of its effects on urine $\mathrm{pH}$.

Several experimental therapies are under investigation for treating patients with crush injuries. Free radical-induced oxidant injury has emerged as one of the most important mechanisms of rhabdomyolysis and renal failure. Free radical scavengers have been shown to reduce the magnitude of muscle necrosis caused by ischemia-reperfusion injury [88], and the administration of antioxidants such as glutathione and vitamin $\mathrm{E}$ analogs improve renal function in experimental models [67]. As mentioned previously, desferrioxamine [68,73,89], PAF receptor blockers [61], and the endothelin receptor antagonist bosentan [57] have been shown to reduce the direct toxic effects of myoglobin on the kidney in experimental models of myoglobinuric renal failure. In addition, dantrolene inhibits the release of $\mathrm{Ca}^{++}$from the sarcoplasmic reticulum and accelerates the return of intracellular levels of $\mathrm{Ca}^{++}$to baseline [90]. This may help to lessen the degree of muscle cell death in patients with crush injuries. The loop diuretic, furosemide, was able to convert 7 of 14 patients with oliguric renal failure to nonoliguric renal failure in a series of 200 patients with traumatic rhabdomyolysis from severe beatings in South Africa [8]. Loop diuretics, however, have the theoretical disadvantage of acidifying the urine, which may increase the amount of myoglobin toxicity.

\section{Treatment of $A R F$}

Despite adequate resuscitation and prophylaxis against myoglobinuric renal injury, up to one third of patients with rhabdomyolysis will develop ARF. These patients require some form of renal replacement therapy. Daily hemodialysis or continuous hemodialysis/hemofiltration will correct the fluid and electrolyte abnormalities that accompany rhabdomyolysis and renal failure. Continuous hemodialysis and hemofiltration do not cause hypotension and cardiac arrhythmias that are associated with the rapid fluid shifts that occur with intermittent hemodialysis [91]. This may make these modalities more appropriate in critically ill patients with hemodynamic instability.

Intractable hyperkalemia and acidosis, refractory to volume expansion and bicarbonate administration, are the main early threats to survival in patients with rhabdomyolysis, and dialysis must be instituted promptly. The hypocalcemia that accompanies rhabdomyolysis should not be corrected unless there is danger of a hyperkalemic arrhythmia [92], for most of the infused calcium is deposited in injured muscles and may aggravate the pathogenesis of rhabdomyolysis and lead to metastatic calcification [93]. 


\section{Treatment of compartment syndrome}

When compartment syndrome is suspected based on mechanism of injury and clinical findings, muscle compartment pressures should be measured directly. The most commonly used compartment pressure measurement device is the Stryker STIC Device (Stryker Corporation, Kalamazoo, Michigan). Any clinical electronic arterial pressure monitoring device, however, can be adopted to perform compartment pressure measurements. Normal compartment pressures range from 0 to $15 \mathrm{~mm} \mathrm{Hg}$ [94]. Compartment pressures in excess of 30 to $50 \mathrm{~mm} \mathrm{Hg}$ produce clinically significant muscle ischemia [95-97]. Patients with higher diastolic pressures are able to tolerate higher tissue pressures without ischemic damage, and therefore a fasciotomy is recommended when the compartment pressure approaches $20 \mathrm{~mm} \mathrm{Hg}$ below diastolic pressure [94]. Hypotensive trauma patients may experience significant muscle ischemia at lower compartment pressures.

The most common location of compartment syndrome is in the lower leg. A lower leg fasciotomy involves incising the skin and fascia overlying its four muscle compartments: anterior, lateral, superficial posterior, and deep posterior. One and two-incision techniques have been described [94]. Compartment syndrome also can be encountered in the forearm, thigh, and buttock muscle groups. The purpose of a fasciotomy is to decrease intracompartmental pressure and restore perfusion to ischemic muscle. To be effective in preventing irreversible ischemic muscle damage, however, a fasciotomy must be performed early. Once irreversible ischemic damage is present, as evidenced by the onset of painlessness or paralysis, there will be little functional recovery and a higher rate of infection [98].

Experimental studies have found that irreversible muscle and nerve damage occur after 6 to 8 hours of total ischemia [94]. Several studies have attempted to define a specific cutoff period, after injury, that represents the onset of irreversible damage and precludes the use of fasciotomy. Sheridan and Matsen [99] found that only $8 \%$ of patients who underwent fasciotomy more than 12 hours after the onset of symptoms of compartment syndrome had restoration of normal function. They also reported a $46 \%$ infection rate and a $21 \%$ amputation rate. A meta-analysis by Bradley [98] found fasciotomy in patients with paralysis to be unsatisfactory in over $80 \%$ of cases.

In a retrospective study of five patients who underwent fasciotomy 35 to 96 hours after injury, one patient died of sepsis and multi-organ failure, and the other four required amputation, either because of local infection and sepsis (three patients) or the presence of an insensate, functionless limb (one patient). Finkelstein [100] concluded that delayed fasciotomy converts a closed injury into an open one, and cannot correct the muscle or nerve damage that already has occurred. Better et al [50] also condemned late fasciotomy for its potential to produce uncontrollable infection in necrotic muscle. They went on to state that the excision of noninfected, necrotic tissue is not essential and may delay healing. Reis and Michaelson [85] had to perform above-knee amputations for uncontrolled sepsis in 
three of six patients who previously had undergone fasciotomies more than 24 hours after injury. They concluded that the sequelae of infection in a crushed extremity are much worse than the late muscle contracture that may result from fibrosis of muscle.

Two years after the earthquake in Kobe, Japan, Matsuoka et al [101] performed follow-up examinations in 42 crush syndrome patients to investigate sensory and motor functions of the affected lower extremities. Fasciotomies were done in 17 patients, and all were performed after 12 hours. Severe disabilities related to the lower extremity were found in $47 \%$ of patients who underwent fasciotomy and in $16 \%$ of those who did not. Although the two groups of patients were not similar, multivariate analysis suggested that delayed rescue, delayed fasciotomy, and radical debridement all worsen the patient's prognosis.

It has been suggested that fasciotomy should not be performed more than 10 to 12 hours after injury in patients with compartment syndrome. Seddon [102] found some degree of spontaneous muscle recovery up to 3 months after injury, and suggested that an interval fasciotomy (6 to 12 months after injury) combined with reconstructive procedures should be able to correct most ischemic contractures. This approach may offer the best physical outcome for patients with crush injuries and compartment syndrome that are not addressed within 12 hours.

Amputation may be required when massive extremity necrosis progresses to an extent that limb salvage is not possible. Because necrotic muscle is a rich source of myoglobin, potassium, and tissue thromboplastin, retention of a nonsalvageable limb can be life-threatening. Necrotic muscle may become infected and serve as a source of uncontrollable sepsis. If it becomes evident that amputation will be required, early amputation is tolerated better than late amputation both physiologically and emotionally [103].

\section{Assessing risk of renal failure}

Several studies have attempted to identify which patients will progress to myoglobinuric renal failure based on their laboratory values. The prospective identification of patients who are at high risk of developing acute renal dysfunction (ARD; serum creatinine, $\mathrm{Cr}$ greater than $2.0 \mathrm{mg} / \mathrm{dL}$ without need for dialysis) or ARF would allow therapy to be delivered to those most likely to benefit. Serum CK levels and serum and urine myoglobin levels have been proposed as screening tools, but no consensus exists.

A series of 200 victims of severe beatings in South Africa found that base deficit, delay in treatment, and CK levels were significant risk factors for the development of ARD and death [8]. Similarly, in a study of 157 patients, Ward [18] found that patients with a peak serum CK level greater than 16,000 U/L had the highest risk of developing ARD. Notably, $90 \%$ of patients had their CK levels peak within 24 hours of admission. A retrospective review of 93 patients with severe rhabdomyolysis (serum CK greater than $5000 \mathrm{U} / \mathrm{L}$ ) found that patients with a peak CK level of greater than 15,000 U/L had significantly higher rates of ARD 
(72\% versus $38 \%, P<0.01)$, hyperkalemia $(22 \%$ versus $7 \%, P<0.05)$, and hypocalcemia $(63 \%$ versus $28 \%, P<0.05)$. Additionally, the patients with ARD had a higher mortality compared with those patients with normal renal function (51\% versus $17 \%, P<0.01)$ [104].

A recent analysis of 372 patients with crush syndrome after the 1995 earthquake in Kobe, Japan, demonstrated a significant correlation between peak serum CK levels and the number of extremities crushed [14]. In addition, patients with a peak CK level greater than 75,000 U/L had a higher rate of ARF and mortality than those with a peak CK less than 75,000 U/L (84\% versus $39 \%, P<0.01$ and $4 \%$ versus $17 \%, P<0.05$, respectively). Eneas et al [84] found that only patients with a peak CK greater than 20,000 U/L failed to respond to a mannitol-bicarbonate diuresis and went on to require dialysis. The nonresponders also had significantly higher serum phosphate levels and hematocrit readings upon admission, indicative of more severe muscle injury and hemoconcentration.

Several studies have attempted to predict the development of renal failure using serum or urine myoglobin levels. A prospective study of eight patients by Feinfeld [105] found that four of five patients with urine myoglobin levels greater than $1000 \mathrm{ng} / \mathrm{mL}$ (normal $=<10 \mathrm{ng} / \mathrm{mL}$ ) developed ARD, while none of the three patients with urine myoglobin levels less than $300 \mathrm{ng} / \mathrm{mL}$ developed ARD. Of note, initial CK levels were not found to be predictive of renal dysfunction in this study. Another report found that elevated urine myoglobin levels greater than $20,000 \mathrm{ng} / \mathrm{mL}$ were associated with a significantly increased risk of renal dysfunction [106].

The conclusions from these studies of patients with rhabdomyolysis and myoglobinuria must be viewed with caution because of their heterogeneity. They often used varying definitions of renal failure, ranging from an elevation in serum $\mathrm{Cr}$ of greater than $2.0 \mathrm{mg} / \mathrm{dL}$ to the need for hemodialysis. There also were large variations in study design and patient selection; the number of patients studied ranged from 8 to 372; there was an inconsistent amount of time between injury and treatment, and the treatment of myoglobinuria differed in each of the studies.

Despite conflicting reports regarding the utility of $\mathrm{CK}$ and myoglobin levels, several conclusions can be drawn. CK levels can be obtained in less than 1 hour; they are readily available in most institutions, and they are less expensive than myoglobin levels (\$15 versus \$97 in the authors' laboratory). Serum and urine myoglobin levels can take over 24 hours to obtain, depending on the distance from one's hospital to the regional laboratory that has the capability to perform the assay. In addition, myoglobin has faster elimination kinetics than $\mathrm{CK}$, making it a less sensitive marker of muscle injury [107]. In a prospective study of 13 patients with rhabdomyolysis, Lappalainen [108] found that the average times to reach the $50 \%$ level of initial values were 12 hours for myoglobin and 42 hours for CK $(P<0.01)$. In a review of laboratory investigations, Beetham [109] concluded that serum CK levels should be used to screen patients with suspected rhabdomyolysis and that there is no reason for laboratories to have assays for myoglobin available until further studies are able to demonstrate its utility. 


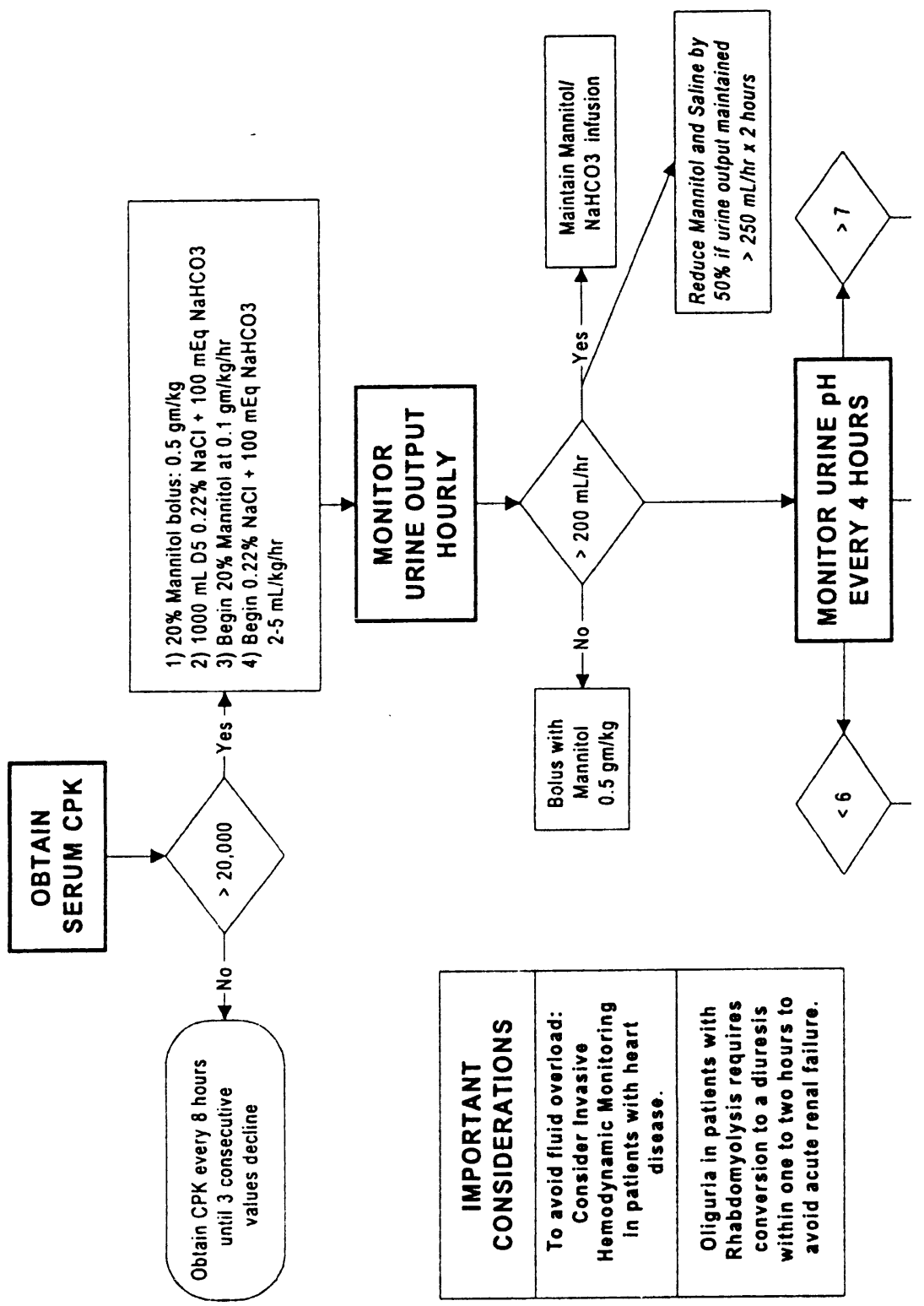




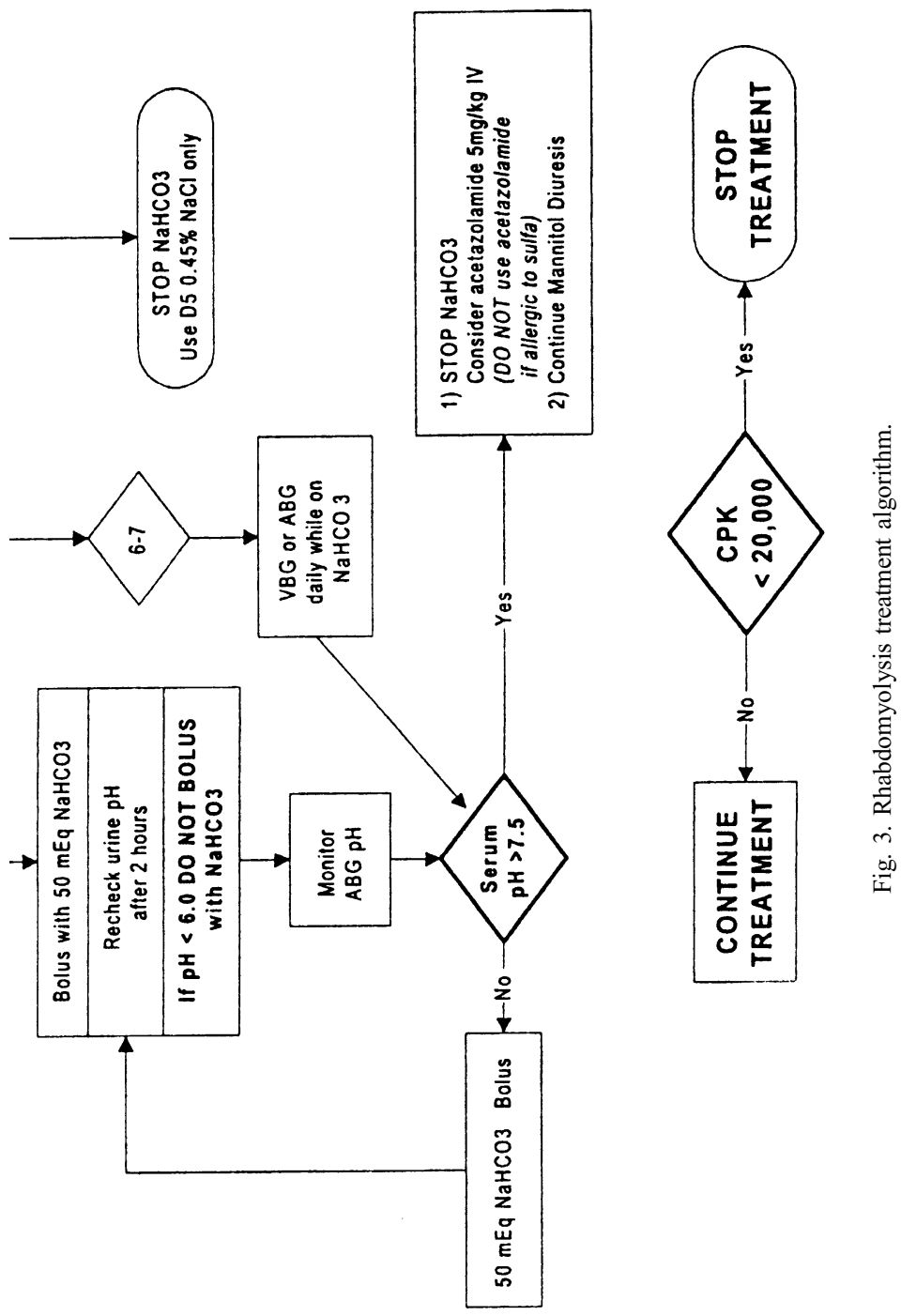




\section{Treatment algorithm}

A treatment algorithm for patients with rhabdomyolysis was established at the authors' institution in 1992 (Fig. 3). Based on a review of the literature, a forced alkaline diuresis with mannitol and bicarbonate was chosen as the authors' method of preventing renal failure in high-risk patients. A serum CK level of 20,000 U/L is the current threshold for identifying those patients who are at risk and require treatment. The primary objective of the algorithm is to prevent ARF. The treatment goals are (1) to achieve a urine output of $200 \mathrm{~mL}$ per hour, (2) to maintain urine $\mathrm{pH}$ between 6 and 7, (3) to keep serum $\mathrm{pH}$ below 7.50, and (4) to achieve hemodynamic stability and prevent volume overload. Treatment begins with a bolus of $1 \mathrm{~L}$ of D5 $0.22 \% \mathrm{NaCl}+100 \mathrm{mEq} \mathrm{NaHCO} 3$ over 30 minutes, followed by an infusion at 2 to $5 \mathrm{~mL} / \mathrm{kg}$ per hour. At the same time, a bolus of $0.5 \mathrm{gm} / \mathrm{kg}$ $20 \%$ mannitol is given over 15 minutes and followed by an infusion at $0.1 \mathrm{gm} / \mathrm{kg}$ per hour. Infusions and additional boluses are titrated to maintain a urine output of $200 \mathrm{~mL}$ per hour. When serum $\mathrm{pH}$ exceeds 7.45 , or urine $\mathrm{pH}$ remains below 6.0 , the administration of acetazolamide can help to increase the excretion of bicarbonate in the urine. The patient should be monitored for hypernatremia, hyperosmolality (normal range in the authors' laboratory 275 to $295 \mathrm{mOsm} / \mathrm{kg}$ water), and volume overload, as these are possible complications of treatment.

This treatment algorithm represents a suggested method of managing patients with rhabdomyolysis, but it has not been validated in a prospective randomized controlled trial. Further research is needed to identify the specific components of treatment that lead to significant improvements in outcome.

\section{Mass casualties}

During the last 15 years, several natural disasters have generated large numbers of patients with rhabdomyolysis and, consequently, enhanced the understanding of the presentation of the crush syndrome and the importance of instituting early treatment to prevent renal failure and death. Earthquakes have the unique ability to affect the widespread collapse of buildings, trapping victims beneath their fallen debris and inflicting crush injuries. In addition to destroying homes and businesses, earthquakes disrupt roads, communication lines, and hospitals, making the delivery of care to injured patients difficult at best. Another confounding factor is that several hundred patients may require dialysis to prevent life-threatening hyperkalemia at roughly the same time. This often overwhelms local health care systems and contributes to mortality [10].

On Dec. 7, 1988, an earthquake with a magnitude of 6.9 on the Richter scale struck near Spitak, Armenia, in the former Soviet Union. Official estimates of the number of people killed range from 26,000 to 50,000 [10]. Over 600 patients developed renal failure and required dialysis [110]. There was a paucity of patients with major trauma to the head, chest, or abdomen seen in hospitals after the earthquake, suggesting that these injuries lead to asphyxiation and are generally 
fatal when they occur in the setting of a disaster that generates significant crush injuries $[15,17]$. It became clear early on that the local medical resources were going to be insufficient to care for the large number of injured patients, and dialysis teams from several countries were flown to the area. Relief efforts, however, were hindered by poor coordination, a lack of sufficient equipment, and their arrival on the scene several days after the disaster [107]. A group of nephrologists from London were one of the teams deployed to the disaster, and they concluded that a permanent relief team, available to depart at a few hours notice, would be required to achieve optimal outcomes [10]. The International Society of Nephrology created a Disaster Relief Task Force (DRTF) in 1995 to prevent and treat crush injuryinduced ARF that occurs following traumatic rhabdomyolysis [111].

The European branch of the DRTF was dispatched to Northwest Turkey on Aug. 17, 1999, when an earthquake with a magnitude of 7.4 on the Richter scale struck Marmara. Personnel, equipment, and supplies were delivered to assist in approximately 5000 dialysis sessions in 462 patients with ARF caused by traumatic rhabdomyolysis. The observed mortality rate of $19 \%$ in these patients was a significant improvement on previous relief efforts [11].

The Hanshin-Awaji earthquake struck the island of Japan near the city of Kobe on Jan. 17, 1995. It measured 7.2 on the Richter scale, injured 41,000 people, and killed approximately 5500 people. A review of the medical records of 95 hospitals identified 372 patients with the crush syndrome; 202 patients developed ARD, including 78 people who needed dialysis. The patients requiring dialysis were significantly older (54 versus 45 years, $P<0.05)$ and experienced a longer delay from injury to treatment ( 8 versus 3.6 hours, $P<0.05$ ). As stated previously, peak CK levels correlated with the number of injured extremities, and a peak CK of greater than 75,000 was associated with a significantly higher prevalence of ARF and death [14]. A retrospective analysis of eight patients who developed ARF after the Kobe earthquake found that serum CK levels and serum myoglobin levels significantly correlated with serum potassium concentrations $(\mathrm{r}=0.87, P=0.005$, and $\mathrm{r}=0.81, P=0.03$, respectively) [13]. Another retrospective review of 14 earthquake survivors concluded that renal function after crush injury is dependent on injury severity (peak CK levels) and initial fluid resuscitation [12]. Several factors were found that contributed to the morbidity of patients who suffered crush injuries: local physicians' unfamiliarity with the crush syndrome, the destruction of local medical facilities, and a delay in transport to tertiary care hospitals.

Better [50] has made several recommendations regarding relief efforts in future disasters. He suggests that teams outfitted with continuous arteriovenous hemofiltration equipment should be available for rapid transport to the site of a rescue operation. This mode of renal replacement therapy is ideal in the setting of a natural disaster, for it allows hemodialysis with only $12 \mathrm{~L}$ of water every 12 hours; it does not require electricity or pumps; it does not necessitate dialysate delivery; its equipment is disposable, and large quantities of potassium can be removed. Better also emphasizes the need to re-establish communication networks immediately following future disasters, as this has limited previous relief efforts. 


\section{Summary}

Crush injuries resulting in traumatic rhabdomyolysis are an important cause of acute renal failure. Ischemia-reperfusion is the main mechanism of muscle injury. Intravascular volume depletion and renal hypoperfusion, combined with myoglobinuria, result in renal dysfunction. The infusion of intravenous fluids before extrication or soon after injury may lessen the severity of the crush syndrome. Serum CK levels can be used to screen patients with crush injuries to determine injury severity. Once intravascular volume has been stabilized, and the presence of urine flow has been confirmed, a forced mannitol-alkaline diuresis for prophylaxis against hyperkalemia and acute renal failure should be instituted. If an extremity compartment syndrome is suspected, one should have a low threshold for checking the intracompartmental pressures. Further studies are needed to demonstrate if any treatment regimen is truly superior to early, aggressive crystalloid infusion.

\section{References}

[1] Fleisher R. Ueber eine form von Haemoglbinuric bein Menschen. Berl Klin Wochenschr 1881; 18:691.

[2] Meyer-Betz F. Beobachtungen an einem Eigentartigen mit Muskellahmungen ver bunden fall van Haemoglobinuric. Dtsch Arch Klin Med 1911;101:85.

[3] Bywaters E, Beall D. Crush injuries with impairment of renal function. BMJ 1941;1:427-32.

[4] Beall D, Bywaters E, Belsey R, Miles J. A case of crush injury with renal failure. BMJ 1941;1: $432-4$.

[5] Bywaters E, Stead J. The production of renal failure following injection of solutions containing myohaemoglobin. Quarterly Journal of Experimental Physiology 1944;33:53.

[6] Jones R. Crush syndrome in a Cornish tin mine. Injury 1984;15:282.

[7] Bentley G, Jeffereys T. The crush syndrome in coal miners. J Bone Joint Surg Br 1968;50: $588-94$.

[8] Knottenbelt JD. Traumatic rhabdomyolysis from severe beating - experience of volume diuresis in 200 patients. Journal of Trauma-Injury Infection \& Critical Care 1994;37(2):214-9.

[9] Noji EK, Kelen GD, Armenian HK, Oganessian A, Jones NP, Sivertson KT. The 1988 earthquake in Soviet Armenia: a case study. Ann Emerg Med 1990;19(8):891-7.

[10] Richards NT, Tattersall J, McCann M, Samson A, Mathias T, Johnson A. Dialysis for acute renal failure due to crush injuries after the Armenian earthquake [erratum appears in BMJ 1989; 298(6674):655]. BMJ 1989;298(6671):443-5.

[11] Sever MS, Erek E, Vanholder R, Akoglu E, Yavuz M, Ergin H, et al. The Marmara earthquake: epidemiological analysis of the victims with nephrological problems. Kidney Int 2001;60(3): 1114-23.

[12] Shimazu T, Yoshioka T, Nakata Y, Ishikawa K, Mizushima Y, Morimoto F, et al. Fluid resuscitation and systemic complications in crush syndrome: 14 Hanshin-Awaji earthquake patients. Journal of Trauma-Injury Infection \& Critical Care 1997;42(4):641-6.

[13] Oda Y, Shindoh M, Yukioka H, Nishi S, Fujimori M, Asada A. Crush syndrome sustained in the 1995 Kobe, Japan, earthquake: treatment and outcome. Ann Emerg Med 1997;30(4):507-12.

[14] Oda J, Tanaka H, Yoshioka T, Iwai A, Yamamura H, Ishikawa K, et al. Analysis of 372 patients with crush syndrome caused by the Hanshin-Awaji earthquake [discussion]. Journal of Trauma-Injury Infection \& Critical Care 1997;42(3):470-5.

[15] Pretto EA, Angus DC, Abrams JI, Shen B, Bissell R, Ruiz Castro VM, et al. An analysis of prehospital mortality in an earthquake. Disaster Reanimatology Study Group. Prehospital Disaster Med 1994;9(2):107-17. 
[16] Gabow P, Kaehny W, Kelleher S. The spectrum of rhabdomyolysis. Medicine 1982;62:141.

[17] Slater M, Mullins R. Rhabdomyolysis and myoglobinuric renal failure in trauma and surgical patients: a review. J Am Coll Surg 1998;186(6):693-716.

[18] Ward MM. Factors predictive of acute renal failure in rhabdomyolysis. Arch Intern Med 1988; 148(7):1553-7.

[19] Knochel JP. Rhabdomyolysis and myoglobinuria. Annu Rev Med 1982;33:435-43.

[20] Ali H, Nieto JG, Rhamy RK, Chandarlapaty SK, Vaamonde CA. Acute renal failure due to rhabdomyolysis associated with the extreme lithotomy position. Am J Kidney Dis 1993;22(6): $865-9$.

[21] Bruce RG, Kim FH, McRoberts W. Rhabdomyolysis and acute renal failure following radical perineal prostatectomy. Urology 1996;47(3):427-30.

[22] Nimmo GR, Stewart SM, English PJ. Myoglobinuric acute renal failure associated with major urological surgery—an avoidable problem? Intensive Care Med 1988;14(3):244-5.

[23] Guzzi LM, Mills LM, Greenman P. Rhabdomyolysis, acute renal failure, and the exaggerated lithotomy position. Anesth Analg 1993;77(3):635-7.

[24] Bildsten SA, Dmochowski RR, Spindel MR, Auman JR. The risk of rhabdomyolysis and acute renal failure with the patient in the exaggerated lithotomy position. J Urol 1994;152:1970-2.

[25] Mathes DD, Assimos DG, Donofrio PD. Rhabdomyolysis and myonecrosis in a patient in the lateral decubitus position. Anesthesiology 1996;84(3):727-9.

[26] Szewczyk D, Ovadia P, Abdullah F, Rabinovici R. Pressure-induced rhabdomyolysis and acute renal failure. Journal of Trauma-Injury Infection \& Critical Care 1998;44(2):384-8.

[27] Tountas CP, Bergman RA. Tourniquet ischemia: ultrastructural and histochemical observations of ischemic human muscle and of monkey muscle and nerve. Journal of Hand SurgeryAmerican Volume 1977;2(1):31-7.

[28] Sapega AA, Heppenstall RB, Chance B, Park YS, Sokolow D. Optimizing tourniquet application and release times in extremity surgery. A biochemical and ultrastructural study. J Bone Joint Surg Am 1985;67(2):303-14.

[29] Singh U, Scheld WM. Infectious etiologies of rhabdomyolysis: three case reports and review [comment]. Clin Infect Dis 1996;22(4):642-9.

[30] Frank D, Fisher J. Complications of electrical injury. In: Greenfield L, editor. Complications in surgery and trauma. Philadelphia: Lippincott-Raven; 1990.

[31] Bhatt DL, Gaylor DC, Lee RC. Rhabdomyolysis due to pulsed electric fields. Plastic and Reconstructive Surgery 1990;86(1):1-11.

[32] Hansen-Flaschen J, Cowen J, Raps EC. Neuromuscular blockade in the intensive care unit. More than we bargained for. Am Rev Respir Dis 1993;147(1):234-6.

[33] Cushing $\mathrm{H}$. The basophil adenoma of the pituitary body and their clinical manifestations. Johns Hopkins Med J 1932;50:137.

[34] Kupfer Y, Namba T, Kaldawi E, Tessler S. Prolonged weakness after long-term infusion of vecuronium bromide [comment]. Ann Intern Med 1992;117(6):484-6.

[35] Douglass JA, Tuxen DV, Horne M, Scheinkestel CD, Weinmann M, Czarny D, et al. Myopathy in severe asthma. Am Rev Respir Dis 1992;146(2):517-9.

[36] Baker PF, Blaustein MP, Hodgkin AL, Steinhardt RA. The influence of calcium on sodium efflux in squid axons. J Physiol 1969;200(2):431-58.

[37] Christensen O. Mediation of cell volume regulation by $\mathrm{Ca} 2+$ influx through stretch-activated channels. Nature 1987;330(6143):66-8.

[38] Cheung JY, Bonventre JV, Malis CD, Leaf A. Calcium and ischemic injury. N Engl J Med 1986;314(26):1670-6.

[39] Chien KR, Abrams J, Serroni A, Martin JT, Farber JL. Accelerated phospholipid degradation and associated membrane dysfunction in irreversible, ischemic liver cell injury. J Biol Chem 1978;253(13):4809-17.

[40] Wrogemann K, Pena SD. Mitochondrial calcium overload: a general mechanism for cellnecrosis in muscle diseases. Lancet 1976;1(7961):672-4.

[41] Suzuki M, Inauen W, Kvietys PR, Grisham MB, Meininger C, Schelling ME, et al. Superoxide 
mediates reperfusion-induced leukocyte-endothelial cell interactions. Am J Physiol 1989;257: H1740-1745.

[42] Harris AG, Skalak TC. Effects of leukocyte activation on capillary hemodynamics in skeletal muscle. Am J Physiol 1993;264(3 Pt 2):H909-16.

[43] Shackford S, Rich N. Peripheral Vascular Injury. In: Mattox K, Feliciano D, Moore E, editors. Trauma. 4th edition. San Francisco: McGraw-Hill; 1996. p. 1011-44.

[44] Recknagel R, Glende E, Hruszkewycz A. Chemical mechanisms of carbon tetrachloride toxicity. In: Pryor W, editor. Free radicals in biology, volume 3. New York: Academic Press; 1977.

[45] Harris K, Walker PM, Mickle DA, Harding R, Gatley R, Wilson GJ, et al. Metabolic response of skeletal muscle to ischemia. Am J Physiol 1986;250:H213-220.

[46] Sanderson RA, Foley RK, McIvor GW, Kirkaldy-Willis WH. Histological response on skeletal muscle to ischemia. Clinical Orthop 1975;113:27-35.

[47] Diana JN, Laughlin MH. Effect of ischemia on capillary pressure and equivalent pore radius in capillaries of the isolated dog hind limb. Circ Res 1974;35(1):77-101.

[48] Miller SH, Price G, Buck D, Neeley J, Kennedy TJ, Graham III WP, et al. Effects of tourniquet ischemia and postischemic edema on muscle metabolism. Journal of Hand Surgery-American Volume 1979;4(6):547-55.

[49] Strock PE, Majno G. Microvascular changes in acutely ischemic rat muscle. Surg Gynecol Obstet 1969;129(6):1213-24.

[50] Better OS, Stein JH. Early management of shock and prophylaxis of acute renal failure in traumatic rhabdomyolysis [comment]. N Engl J Med 1990;322(12):825-9.

[51] Blalock A. Experimental shock: the probable cause for the reduction in the blood pressure following mild trauma to as extremity. Arch Surg 1931;22:598-609.

[52] Bywaters E, Popjak G. Experimental crushing injury: peripheral circulatory collapse and other effects of muscle necrosis in the rabbit. Surg Gynecol Obstet 1942;75:612-27.

[53] Ron D, Taitelman U, Michaelson M, Bar-Joseph G, Bursztein S, Better OS. Prevention of acute renal failure in traumatic rhabdomyolysis. Arch Intern Med 1984;144(2):277-80.

[54] Badr KF, DeBoer DK, Takahashi K, Harris RC, Fogo A, Jacobson HR. Glomerular responses to platelet-activating factor in the rat: role of thromboxane A2. Am J Physiol 1989;256(1 Pt 2): F35-43.

[55] Yanagisawa M, Kurihara H, Kimura S, Tomobe Y, Kobayashi M, Mitsui Y, et al. A novel potent vasoconstrictor peptide produced by vascular endothelial cells [comment]. Nature 1988; 332(6163):411-5.

[56] Holt SG, Moore KP. Pathogenesis and treatment of renal dysfunction in rhabdomyolysis [comment]. Intensive Care Med 2001;27(5):803-11.

[57] Karam H, Bruneval P, Clozel JP, Loffler BM, Bariety J, Clozel M. Role of endothelin in acute renal failure due to rhabdomyolysis in rats. J Pharmacol Exp Ther 1995;274(1):481-6.

[58] Schlondorff D, Goldwasser P, Neuwirth R, Satriano JA, Clay KL. Production of plateletactivating factor in glomeruli and cultured glomerular mesangial cells. Am J Physiol 1986; 250:F1123-1127.

[59] Hebert RL, Sirois P, Braquet P, Plante GE. Hemodynamic effects of PAF-acether on the dog kidney. Prostaglandins Leukot Med 1987;26(3):189-202.

[60] Braquet P, Touqui L, Shen TY, Vargaftig BB. Perspectives in platelet-activating factor research. Pharmacol Rev 1987;39(2):97-145.

[61] Lopez-Farre A, Gomez-Garre D, Bernabeu F, Ramon y Cajal S, Perez-Rodrigo P, Braquet P, et al. Platelet-activating factor mediates glycerol-induced acute renal failure in rats. Clin Sci (Lond) 1990;79(6):551-8.

[62] Bunn HF, Jandl JH. The renal handling of hemoglobin. II. Catabolism. J Exp Med 1969; 129(5):925-34.

[63] Zager RA. Studies of mechanisms and protective maneuvers in myoglobinuric acute renal injury. Lab Invest 1989;60(5):619-29.

[64] Baker S, Dodds E. Obstruction of the renal tubules during the excretion of haemoglobin. Br J Exp Pathol 1925;6:247-60. 
[65] Myers BD, Chui F, Hilberman M, Michaels AS. Transtubular leakage of glomerular filtrate in human acute renal failure. Am J Physiol 1979;237(4):F319-25.

[66] Oken DE, Arce ML, Wilson DR. Glycerol-induced hemoglobinuric acute renal failure in the rat. I. Micropuncture study of the development of oliguria. J Clin Invest 1966;45(5):724-35.

[67] Abul-Ezz SR, Walker PD, Shah SV. Role of glutathione in an animal model of myoglobinuric acute renal failure. Proc Natl Acad Sci U S A 1991;88(21):9833-7.

[68] Shah SV, Walker PD. Evidence suggesting a role for hydroxyl radical in glycerol-induced acute renal failure. Am J Physiol 1988;255:F438-443.

[69] Salahudeen AK, Wang C, Bigler SA, Dai Z, Tachikawa H. Synergistic renal protection by combining alkaline-diuresis with lipid peroxidation inhibitors in rhabdomyolysis: possible interaction between oxidant and nonoxidant mechanisms. Nephrol Dial Transplant 1996; 11(4):635-42.

[70] Zager RA. Mitochondrial free radical production induces lipid peroxidation during myohemoglobinuria. Kidney Int 1996;49(3):741-51.

[71] Bunn HF, Jandl JH. Exchange of heme among hemoglobin molecules. Proc Natl Acad Sci U S A 1966;56(3):974-8.

[72] Moore KP, Holt SG, Patel RP, Svistunenko DA, Zackert W, Goodier D, et al. A causative role for redox cycling of myoglobin and its inhibition by alkalinization in the pathogenesis and treatment of rhabdomyolysis-induced renal failure. J Biol Chem 1998;273(48):31731-7.

[73] Zager RA. Combined mannitol and deferoxamine therapy for myohemoglobinuric renal injury and oxidant tubular stress. Mechanistic and therapeutic implications. J Clin Invest 1992;90(3): $711-9$.

[74] Cooper CE, Green ES, Rice-Evans CA, Davies MJ, Wrigglesworth JM. A hydrogen-donating monohydroxamate scavenges ferryl myoglobin radicals. Free Radic Res 1994;20(4): $219-27$.

[75] Morrow JD, Hill KE, Burk RF, Nammour TM, Badr KF, Roberts II LJ. A series of prostaglandin F2-like compounds are produced in vivo in humans by a noncyclooxygenase, free radical-catalyzed mechanism. Proc Natl Acad Sci U S A 1990;87(23):9383-7.

[76] Holt S, Reeder B, Wilson M, Harvey S, Morrow JD, Roberts II LJ, et al. Increased lipid peroxidation in patients with rhabdomyolysis. Lancet 1999;353(9160):1241.

[77] Vetterlein F, Hoffmann F, Pedina J, Neckel M, Schmidt G. Disturbances in renal microcirculation induced by myoglobin and hemorrhagic hypotension in anesthetized rat. Am J Physiol 1995;268:F839-46.

[78] Maree A, Peer G, Schwartz D, Serban I, Blum M, Wollman Y, et al. Role of nitric oxide in glycerol-induced acute renal failure in rats. Nephrol Dial Transplant 1994;9(Suppl 4):78-81.

[79] Gorbunov NV, Osipov AN, Day BW, Zayas-Rivera B, Kagan VE, Elsayed NM. Reduction of ferrylmyoglobin and ferrylhemoglobin by nitric oxide: a protective mechanism against ferryl hemoprotein-induced oxidations. Biochemistry 1995;34(20):6689-99.

[80] Dee G, Rice-Evans C, Obeyesekera S, Meraji S, Jacobs M, Bruckdorfer KR. The modulation of ferryl myoglobin formation and its oxidative effects on low density lipoproteins by nitric oxide. FEBS Lett 1991;294:38-42.

[81] Odeh M. The role of reperfusion-induced injury in the pathogenesis of the crush syndrome [comment]. N Engl J Med 1991;324(20):1417-22.

[82] Better OS, Zinman C, Reis DN, Har-Shai Y, Rubinstein I, Abassi Z. Hypertonic mannitol ameliorates intracompartmental tamponade in model compartment syndrome in the dog. Nephron 1991;58(3):344-6.

[83] Ferreira TA, Pensado A, Dominguez L, Aymerich H, Molins N. Compartment syndrome with severe rhabdomyolysis in the postoperative period following major vascular surgery. Anaesthesia 1996;51(7):692-4.

[84] Eneas JF, Schoenfeld PY, Humphreys MH. The effect of infusion of mannitol-sodium bicarbonate on the clinical course of myoglobinuria. Arch Intern Med 1979;139(7):801-5.

[85] Reis ND, Michaelson M. Crush injury to the lower limbs. Treatment of the local injury. J Bone Joint Surg Am 1986;68(3):414-8. 
[86] Heyman SN, Greenbaum R, Shina A, Rosen S, Brezis M. Myoglobinuric acute renal failure in the rat: a role for acidosis? Exp Nephrol 1997;5(3):210-6.

[87] Homsi E, Barreiro MF, Orlando JM, Higa EM. Prophylaxis of acute renal failure in patients with rhabdomyolysis. Ren Fail 1997;19(2):283-8.

[88] Walker PM, Lindsay TF, Labbe R, Mickle DA, Romaschin AD. Salvage of skeletal muscle with free radical scavengers. J Vasc Surg 1987;5(1):68-75.

[89] Paller MS. Hemoglobin- and myoglobin-induced acute renal failure in rats: role of iron in nephrotoxicity. Am J Physiol 1988;255:F539-44.

[90] Lopez JR, Rojas B, Gonzalez MA, Terzic A. Myoplasmic Ca2 + concentration during exertional rhabdomyolysis. Lancet 1995;345(8947):424-5.

[91] Forni LG, Hilton PJ. Continuous hemofiltration in the treatment of acute renal failure [comment]. N Engl J Med 1997;336(18):1303-9.

[92] Knochel JP. Serum calcium derangements in rhabdomyolysis. N Engl J Med 1981;305(3):161 -3.

[93] Meroney W, Arney G, Segar W, Balch H. The acute calcification of traumatized muscle, with particular reference to acute post-traumatic renal insufficiency. J Clin Invest 1957;36:825-32.

[94] Whitesides T, Heckman M. Acute compartment syndrome: update on diagnosis and treatment. J Am Acad Orthop Surg 1996;4:209-18.

[95] Whitesides TE, Haney TC, Morimoto K, Harada H. Tissue pressure measurements as a determinant for the need of fasciotomy. Clinical Orthop 1975;113:43-51.

[96] Matsen III FA, Krugmire Jr RB. Compartmental syndromes. Surg Gynecol Obstet 1978;147(6): 943-9.

[97] Paton DF. The anterior/tibial/syndrome. Practitioner 1981;225(1352):151-3.

[98] Bradley III EL. The anterior tibial compartment syndrome. Surg Gynecol Obstet 1973;136(2): 289-97.

[99] Sheridan GW, Matsen III FA. Fasciotomy in the treatment of the acute compartment syndrome. J Bone Joint Surg Am 1976;58(1):112-5.

[100] Finkelstein JA, Hunter GA, Hu RW. Lower limb compartment syndrome: course after delayed fasciotomy. Journal of Trauma Injury Infection \& Critical Care 1996;40(3):342-4.

[101] Matsuoka T, Yoshioka T, Tanaka H, Ninomiya N, Oda J, Sugimoto H, et al. Long-term physical outcome of patients who suffered crush syndrome after the 1995 Hanshin-Awaji earthquake: prognostic indicators in retrospect. Journal of Trauma-Injury Infection \& Critical Care 2002; 52(1):33-9.

[102] Seddon H. Volkmann's contracture: treatment by excision of the infarct. J Bone Joint Surg Br 1956;38:152.

[103] Bondurant FJ, Cotler HB, Buckle R, Miller-Crotchett P, Browner BD. The medical and economic impact of severely injured lower extremities. Journal of Trauma Injury Infection \& Critical Care 1988;28(8):1270-3.

[104] Veenstra J, Smit WM, Krediet RT, Arisz L. Relationship between elevated creatine phosphokinase and the clinical spectrum of rhabdomyolysis. Nephrol Dial Transplant 1994;9(6):637-41.

[105] Feinfeld DA, Cheng JT, Beysolow TD, Briscoe AM. A prospective study of urine and serum myoglobin levels in patients with acute rhabdomyolysis. Clin Nephrol 1992;38(4):193-5.

[106] Loun B, Astles R, Copeland KR, Sedor FA. Adaptation of a quantitative immunoassay for urine myoglobin. Predictor in detecting renal dysfunction. Am J Clin Pathol 1996;105(4):479-86.

[107] Vanholder R, Sever MS, Erek E, Lameire N. Rhabdomyolysis. J Am Soc Nephrol 2000;11(8): $1553-61$.

[108] Lappalainen H, Tiula E, Uotila L, Manttari M. Elimination kinetics of myoglobin and creatine kinase in rhabdomyolysis: implications for follow-up. Crit Care Med 2002;30(10):2212-5.

[109] Beetham R. Biochemical investigation of suspected rhabdomyolysis. Ann Clin Biochem 2000; 37(Pt 5):581-7.

[110] Collins AJ. Kidney dialysis treatment for victims of the Armenian earthquake. N Engl J Med 1989;320(19):1291-2.

[111] Solek K, Bihari D, Collins A, Eliahou H, Federov V, Kjellstrand C, et al. International dialysis aid in earthquakes and other disasters. Kidney Int 1993;44:479-83. 